\title{
Fresh-Keeping Contract Model of Farmer-Supermarket Direct-Purchase
}

\author{
Zilong Song \\ School of Logistics, Beijing Wuzi University, Beijing, China \\ Email: 337653076@qq.com
}

Received 18 June 2016; accepted 29 July 2016; published 19 August 2016

Copyright (C) 2016 by author and OALib.

This work is licensed under the Creative Commons Attribution International License (CC BY). http://creativecommons.org/licenses/by/4.0/

(c) (i) Open Access

\begin{abstract}
Based on "Farmer-Supermarket Direct-Purchase" as the research background, with farmer, supermarket, logistics company as the main body of research, this paper combines with the thoughts of contract theory, and introduces the concept of fresh-keeping contract of agricultural products. Then, game theory is used to analyze whether to sign the fresh-keeping contract between the supermarket and farmer, supermarket and logistics company. The results indicate that: when farmer and supermarket sign the fresh-keeping contract of fresh agricultural products, the farmer and the supermarket will both benefit from the fresh-keeping contract. Whether supermarket and logistics company sign the fresh-keeping contract is determined by $w_{1}, w_{2}$. If $w_{1}=w_{2}$, the supermarket and the logistics company can sign the fresh-keeping contract or cannot sign the contract. If $w_{1}>w_{2}$, supermarket and logistics company will not choose cooperation. If $w_{1}<w_{2}$, as long as the liquidated damages are in a reasonable range, supermarket and logistics company will both benefit from signing a fresh-keeping contract. This paper can provide a reference for the supermarket, farmers, and logistics companies when signing fresh-keeping contracts.
\end{abstract}

\section{Keywords}

Fresh-Keeping Contract, Farmer-Supermarket Direct-Purchase, Farmer and Supermarket, Supermarket and Logistics Company

Subject Areas: Strategic Management, Supply Chain Management

\section{Introduction}

"Farmer-Supermarket Direct-Purchase" is a new form of circulation that farmers sign a contract with merchant, and then the farmers directly provide agricultural products for supermarkets or markets [1]. This mainly wants to build a platform for high-quality agricultural products into the supermarket. Fresh agricultural products are pro- 
duced by farmers. Whether the quality of agricultural products is up to the standard determines whether the supermarket chooses its cooperation with farmers and the wholesale price of agricultural products [2]. In the process of transporting the fresh agricultural products to supermarkets, its freshness will continue to decrease with time. And, the freshness determines the retail price of agricultural products. The freshness and the price determine the consumer's purchase intention. So in the whole process, how to ensure the standards of agricultural products, how to ensure the freshness of fresh agricultural products in circulation, and how to ensure the final profit of the supermarket are all problems that should be taken into consideration.

Researches about the research of Contract model of "Farmer-Supermarket Direct-Purchase" is also less. Existing literatures have done some related researches about the "Farmer-Supermarket Direct-Purchase" and the fresh-keeping contract of agricultural products. Shen Mo (2010) [3] researched on linkage benefit based on "Farmer-Supermarket Direct-Purchase"; the paper thinks that "Farmer-Supermarket Direct-Purchase" is an innovative business model of agricultural products from farmer to supermarket. It reduces the cost of production and circulation of agricultural products, to ensure the freshness and safety of agricultural products, and promote the establishment of traceability system of agricultural products. Also, it enhances the competitiveness of China agricultural products in the international market, and realizes the profit of farmers, supermarkets and consumers. Zheng Peng (2012) [4] analyzed the surplus distribution and regulation of "Farmer-Supermarket Direct-Purchase" based on the survey data of five provinces and cities in the Midwest. Zheng Guangcai (2011) [5] pointed out that "Farmer-Supermarket Direct-Purchase" is on the initial stage; there are also some problems, such as understanding, planning, policy, management and distribution; and positive policies and powerful measures should be adopted to address the problems. Li Jianping et al. (2013) [6] constructed cooperatives and pacesetting enterprises as the core of the new mode of agricultural production and marketing docking, and put forward the breeding production and marketing of specialized subject, to improve the level of information technology, to promote the socialization of service and to increase the support of the government policy recommendations combined with our country agricultural product production and marketing situation and economic analysis. Shen Min (2011) [7] and Sun Qingzhen (2011) [8] pointed out that the supply and marketing cooperatives should construct the agricultural chain management network, guide the farmers to implement standardized production, and make bigger and stronger professional farmers cooperatives to further promote the "Farmer-Supermarket Direct-Purchase”. In the research of fresh-keeping contract, Wang Jing and Chen Xu (2011) [9] considered the fresh produce with a two-stage model, taking the huge circulation wastage into account, and discussed the optimal procurement decisions for a stochastic demand environment from retailer in one period by establishing the option contract. Wang Lei and Dan Bin (2013) [10] based on the characteristics that fresh agricultures product will deteriorate, constructed a time-varying consumer utility model considering the greenness and price of the fresh agricultural products with utility theory, which depicts the effect that the fresh-keeping has on the consumers purchase decision. In addition, a multi-item ordering model for various fresh agricultural products is developed to analyze the retailer's ordering policies under different unit fresh keeping cost of supplier. Gu Wanrong et al. (2014) [11] according to the deteriorating characteristics of the fresh agricultural product and the variety of consumer preference, developed a time-varying consumer choice model influenced by the greenness and price of the fresh agricultures product. Based on the change of the ordering quantity and potential market capacity, the optimal pricing and optimal input for fresh-keeping of the retailer are analyzed. Wang Chong and Chen Xu (2011) [12] considered the circulation wastage of the fresh produce, and investigated the pricing and coordination with options contracts in a two-stage supply chain that a fresh produce supplier sells to a retailer with Stackelberg model. The optimal option ordering policies for the retailer as well as the optimal pricing policies for the supplier are given when the retailer only orders options. Taking the integrated supply chain as the base model, they give the coordinating conditions for the fresh produce supply chain.

Different from the above literature research, this paper will use the game theory analysis to research that in the mode of "Farmer-Supermarket Direct-Purchase", in what circumstances the supermarket, farmer and logistics company will sign the fresh-keeping contract.

\section{Problem Description}

From the legal sense, in agricultural super docking, farmer and supermarket need to sign a contract, on one hand, farmer produce the agricultural products for supermarket with a certain production cost, on the other hand, supermarket buy agricultural products with a certain wholesale prices. Then, logistics company will transport the 
agricultural products to the destination with a certain transportation cost, and in the end, the supermarket sells agricultural products at a certain retail price. Three party's interests are determined by the quality of fresh agricultural products. Therefore, in this paper, based on the results of previous studies, this paper will design the fresh-keeping contract model of fresh agricultural products, and gives the game analysis of whether the farmer, the supermarket and the logistics company sign the fresh-keeping contract or not.

\section{Model Description}

\subsection{Symbol Definition}

The symbol definition of the model is shown in Table 1.

\subsection{Model Hypothesis}

Assuming that the supermarket is risk neutral, farmer and logistics company are risk averse.

\section{Table 1. Symbol definition.}

\begin{tabular}{|c|c|c|}
\hline Subjects & Variables & Explanation \\
\hline \multirow{3}{*}{ Farmer } & $C F_{i}\left(C F_{i}^{\prime}, C F_{i}^{\prime \prime}\right)$ & $\begin{array}{c}\text { Production cost of agricultural products, } C F_{i}^{\prime}, C F_{i}^{\prime \prime} \text { represents production cost of signing } \\
\text { the keeping fresh contract and not signing the keeping fresh contract respectively. } i \\
\text { expresses different kinds of agricultural products. }\end{array}$ \\
\hline & $\gamma_{1} \in\left[\gamma_{1}^{\prime}, \gamma_{1}^{\prime \prime}\right]$ & $\begin{array}{l}\text { Effort level to ensure the quality of fresh agricultural products. } \gamma_{1}^{\prime}, \gamma_{1}^{\prime \prime} \text { represents } \\
\text { the minimum and maximum level of effort, both in the } 0-1 \text {. }\end{array}$ \\
\hline & $p_{i 1}\left(p_{i 1}^{\prime}, p_{i 1}^{\prime \prime}\right)$ & $\begin{array}{l}\text { Wholesale price of agricultural products, } p_{i 1}^{\prime}, p_{i 1}^{\prime \prime} \text { represents wholesale price of signing } \\
\text { the keeping fresh contract and not signing the keeping fresh contract respectively. }\end{array}$ \\
\hline \multirow{4}{*}{$\begin{array}{l}\text { Super- } \\
\text { market }\end{array}$} & $C M_{i}\left(p_{i 1}\right)$ & $\begin{array}{l}\text { Purchase cost of agricultural products, } C M_{i}^{\prime}, C M_{i}^{\prime \prime} \text { represents purchase cost of signing } \\
\text { the keeping fresh contract and not signing the keeping fresh contract respectively. }\end{array}$ \\
\hline & $Q_{i}$ & The total amount of agricultural products purchased. \\
\hline & $C T_{1}\left(C T_{1}^{\prime}, C T_{1}^{\prime \prime}\right)$ & $\begin{array}{c}\text { Transportation cost of agricultural products, } C T_{1}^{\prime}, C T_{1}^{\prime \prime} \text { represents the payment of the } \\
\text { cost of transport for logistics company of signing the keeping fresh contract and } \\
\text { not signing the keeping fresh contract respectively. }\end{array}$ \\
\hline & $p_{i 2}\left(p_{i 2}^{\prime}, p_{i 2}^{\prime \prime}\right)$ & $\begin{array}{l}\text { Sales price of agricultural products, } p_{i 2}^{\prime}, p_{i 2}^{\prime \prime} \text { represents the sales price of signing } \\
\text { the keeping fresh contract and not signing the keeping fresh contract respectively. }\end{array}$ \\
\hline \multirow{2}{*}{$\begin{array}{l}\text { Logistics } \\
\text { company }\end{array}$} & $C T_{2}$ & The transportation cost of logistics company. \\
\hline & $\gamma_{2} \in\left[\gamma_{2}^{\prime}, \gamma_{2}^{\prime \prime}\right]$ & $\begin{array}{l}\text { Effort level to ensure the quality of fresh agricultural products. } \gamma_{2}^{\prime}, \gamma_{2}^{\prime \prime} \\
\text { represents the minimum and maximum level of effort, both in the } 0-1 \text {. }\end{array}$ \\
\hline \multirow{6}{*}{$\begin{array}{l}\text { Parameter } \\
\text { variable }\end{array}$} & $\theta\left(\gamma_{i}, \varepsilon_{1}\right) \in[0,1]$ & Fresh level of agricultural products, increasing with $\gamma_{i}, \theta\left(\gamma_{i}, \varepsilon_{1}\right)=\theta\left(\gamma_{i}\right) \varepsilon_{1}$ \\
\hline & $\varepsilon_{1}$ & Random variables under uncertain conditions. \\
\hline & $K_{1}, K_{2}$ & Price elasticity of different price. \\
\hline & $\pi F\left(\pi F^{\prime}, \pi F^{\prime \prime}\right)$ & \\
\hline & $\pi M\left(\pi M^{\prime}, \pi M^{\prime \prime}\right)$ & $\begin{array}{l}\text { Respectively, on behalf of the profit of farmer, supermarket and } \\
\text { logistics company in the case of signing the fresh-keeping contract. }\end{array}$ \\
\hline & $\pi T\left(\pi T^{\prime}, \pi T^{\prime \prime}\right)$ & \\
\hline \multirow{2}{*}{ Consumer } & $\varepsilon_{2}$ & Random variables under uncertain conditions. \\
\hline & $D_{i}\left(p_{i 2}, \theta\right)$ & Demand function, is related to fresh level of agricultural products. \\
\hline
\end{tabular}


H1: Assuming that the supermarket and farmers signed a fresh-keeping contract, the supermarket just buy fresh agricultural products which meet quality requirements, and the fresh agricultural products do not meet the quality requirements will not be purchased. $\rho_{1},\left(1-\rho_{1}\right)$ represents the probability that the quality of agricultural products is up to the standard or not respectively.

H2: If the supermarket and logistics company sign the fresh-keeping contract, the logistics company must ensure the freshness of fresh agricultural products within the scope of supermarket can accepts. If the fresh level of agricultural products cannot be guaranteed, then the logistics company must compensate for a certain amount of liquidated damages. $\rho_{2},\left(1-\rho_{2}\right)$ represents the probability whether break the contract or not.

H3: If the agricultural products are not fresh enough, consumers have the right to choose whether to buy. Supermarkets will make a price based on the fresh level of agricultural products. The probability that the fresh produce is sold is $\rho_{3}$, the probability of an incomplete sale is $\left(1-\rho_{3}\right)$.

H4: Assume that the farmer, supermarket and logistics company are all rational people.

\section{Model Establishment}

\subsection{Game Effect Analysis between Supermarket and Farmer}

For farmer, "the planting of what", "where to sell", as well as "how much money to sell" is the most concerned problem. For the supermarket, the "quality" and "customer satisfaction" are the most concerned problems. In the case of agricultural products fresh-keeping contract signed, if the supermarket and farmer are consistent, both sides have income, if the supermarket and farmers do not agree, then there is no cooperative relationship between the two sides, then the expected profit is 0. Establish strategic game matrix between supermarkets and farmers as is shown in Table 2.

In the cultivation of agricultural products, farmers cannot be $100 \%$ to ensure that all agricultural products can meet the requirements of the contract, so set the number of agricultural products which meet the requirements of freshness requirements, that can be represented as $\overline{q_{i}^{j}}\left(\gamma_{1}, \varepsilon_{3}\right), \varepsilon_{3}$ indicates that some of the natural factors that are not resistant to the damage of agricultural products. To make the index of agricultural products meet the requirements is $M\left(\gamma_{1}, \varepsilon_{3}\right)=M\left(\gamma_{1}\right) \varepsilon_{3}$, among the formula, $M\left(\gamma_{1}\right)$ is the increasing function about the $\gamma_{1}$. Then, $\overline{q_{i}^{j}}\left(\gamma_{1}, \varepsilon_{3}\right)=T q_{i}^{j} M\left(\gamma_{1}\right) \varepsilon_{3}$, among this, $T q_{i}^{j}$ is the total amount of agricultural products production of farmer.

Step 1. Both sides sign the contract

$$
\begin{gathered}
E\left(\pi F^{\prime \prime}\right)=\rho_{1}^{\prime \prime} \sum_{i=1}^{I}\left(p_{i 1}^{\prime \prime} \overline{q_{i}^{j}}-C F_{i}^{\prime \prime}\right)+\left(1-\rho_{1}^{\prime \prime}\right) \sum_{i=1}^{I}\left[p_{i 1}^{\prime}\left(T q_{i}^{j}-\overline{q_{i}^{j}}\right)-C F_{i}^{\prime \prime}\right] \\
E_{1}\left(\pi M^{\prime \prime}\right)=\rho_{3}^{\prime \prime}\left[\sum_{i=1}^{I}\left(p_{i 2}^{\prime \prime} D_{i}^{\prime \prime}-C M_{i}^{\prime \prime}\right)-C T_{1}^{\prime \prime}\right]+\left(1-\rho_{3}^{\prime \prime}\right)\left\{\sum_{i=1}^{I}\left[p_{i 2}^{\prime \prime}\left(Q_{i}^{\prime \prime}-D_{i}^{\prime \prime}\right)-C M_{i}^{\prime \prime}\right]-C T_{1}^{\prime \prime}\right\}
\end{gathered}
$$

Step 2. Both sides did not sign the contract

$$
\begin{gathered}
E\left(\pi F^{\prime}\right)=\rho_{1}^{\prime} \sum_{i=1}^{I}\left(p_{i 1}^{\prime} q_{i}^{j}-C F_{i}^{\prime}\right)+\left(1-\rho_{1}^{\prime}\right) \sum_{i=1}^{I}\left[p_{i 1}^{\prime}\left(T q_{i}^{j}-q_{i}^{j}\right)-C F_{i}^{\prime}\right] \\
E_{1}\left(\pi M^{\prime}\right)=\rho_{3}^{\prime}\left[\sum_{i=1}^{I}\left(p_{i 2}^{\prime} D_{i}^{\prime}-C M_{i}^{\prime}\right)-C T_{1}^{\prime}\right]+\left(1-\rho_{3}^{\prime}\right)\left\{\sum_{i=1}^{I}\left[p_{i 2}^{\prime}\left(Q_{i}^{\prime}-D_{i}^{\prime}\right)-C M_{i}^{\prime}\right]-C T_{1}^{\prime}\right\}
\end{gathered}
$$

Step 3. Determination of demand function and basic parameters

Table 2. Game matrix between supermarket and farmer.

\begin{tabular}{ccc}
\hline Expected profit & Sign fresh-keeping contract & Do not sign fresh-keeping contract \\
\hline Sign fresh-keeping contract & $E_{1}\left(\pi M^{\prime \prime}\right), E\left(\pi F^{\prime \prime}\right)$ & 0,0 \\
Do not sign fresh-keeping contract & 0,0 & $E_{1}\left(\pi M^{\prime}\right), E\left(\pi F^{\prime}\right)$ \\
\hline
\end{tabular}


Consumer demand function $D_{i}\left(p_{i 2}, \beta\right)=y_{0} \beta p_{i 2}^{-k} \varepsilon_{2}$

Among them, $\beta=\beta\left(\gamma_{n}, \varepsilon_{2}\right)=\beta\left(\gamma_{n}\right) \varepsilon_{2}$

$\beta$ represents fresh level of fresh agricultural products, consumers will determine whether to purchase or not and the purchase quantity according to the freshness of agricultural products.

For farmer, the cost of production of fresh agricultural products is proportional to the degree of efforts of farmers' inputs, the more effort the investment, the higher the cost of production, and the wholesale price will increase accordingly. So the cost of production and wholesale prices are:

$$
\begin{gathered}
C F_{i}\left(\gamma_{1}, T q_{i}^{j}\right)=C F_{i}\left(T q_{i}^{j}\right) \gamma_{1} \\
p_{i 1}=a \gamma_{1}+p_{i 1}^{0}
\end{gathered}
$$

For the supermarket, the price of fresh agricultural products is related to the fresh level of agricultural products, the more fresher of agricultural products, the price will be more favorable. The total cost of the purchase of agricultural products is related to the agricultural products' prices and wholesale quantities. The cost of transportation in the fresh contract is related to the efforts of the logistics company to keep the fresh degree of the agricultural products. Therefore, the retail price of fresh agricultural products, wholesale costs and transport costs are:

$$
p_{i 2}=a \beta+p_{i 2}^{0}
$$

And, $p_{i 1}^{0}$ is the initial wholesale price, $p_{i 2}^{0}$ is the initial retail price.

$$
C M_{i}=\sum_{j=1}^{J} p_{i 1} \overline{q_{i}^{j}}
$$

So the total purchase volume is $Q_{i}=\sum_{j=1}^{J} \overline{q_{i}^{j}}$, And keep the same.

$$
C T_{1}=C T_{1}\left(Q_{i}\right) \gamma_{2}
$$

Step 4. Game analysis $\rho_{1}^{\prime}=\rho_{1}^{\prime \prime}, \quad \rho_{3}^{\prime}=\rho_{3}^{\prime \prime}$, Formula (1) minus Formula (3):

$$
\begin{aligned}
\Delta E(\pi F)= & E\left(\pi F^{\prime \prime}\right)-E\left(\pi F^{\prime}\right) \\
= & \rho_{1} \sum_{i=1}^{I}\left[p_{i 1}^{0}\left(\overline{q_{i}^{j}}-q_{i}^{j}\right)+a\left(\gamma_{1}^{\prime \prime} q_{i}^{j}-\gamma_{1}^{\prime} q_{i}^{j}\right)-C F_{i}\left(\gamma_{1}^{\prime \prime}-\gamma_{1}^{\prime}\right)\right] \\
& +\left(1-\rho_{1}\right) \sum_{i=1}^{I}\left[p_{i 1}^{0}\left(q_{i}^{j}-\overline{q_{i}^{j}}\right)+a T q_{i}^{j}\left(\gamma_{1}^{\prime \prime}-\gamma_{1}^{\prime}\right)+a\left(\gamma_{1}^{\prime} q_{i}^{j}-\gamma_{1}^{\prime \prime} q_{i}^{j}\right)-C F_{i}\left(\gamma_{1}^{\prime \prime}-\gamma_{1}^{\prime}\right)\right]
\end{aligned}
$$

Because $\overline{q_{i}^{j}}>q_{i}^{j}, \gamma_{1}^{\prime \prime}>\gamma_{1}^{\prime}$, so $\gamma_{1}^{\prime \prime} q_{i}^{j}>\gamma_{1}^{\prime} q_{i}^{j}, \Delta q_{i}=\overline{q_{i}^{j}}-q_{i}^{j}, \Delta \gamma_{1}=\gamma_{1}^{\prime \prime}-\gamma_{1}^{\prime}, \Delta \gamma_{1} q_{i}=\gamma_{1}^{\prime \prime} q_{i}^{j}-\gamma_{1}^{\prime} q_{i}^{j}$ is into the Formula (13), get:

$$
\begin{aligned}
\Delta E(\pi F)= & \rho_{1} \sum_{i=1}^{I}\left(p_{i 1}^{0} \Delta q_{i}+a \Delta \gamma_{1} q_{i}-C F_{i} \Delta \gamma_{1}\right) \\
& +\left(1-\rho_{1}\right) \sum_{i=1}^{I}\left[p_{i 1}^{0}\left(-\Delta q_{i}\right)+a T q_{i}^{j} \Delta \gamma_{1}+a\left(-\Delta \gamma_{1} q_{i}\right)-C F_{i} \Delta \gamma_{1}\right]
\end{aligned}
$$

The Formula (14) can be simplified as follows:

$$
\Delta E(\pi F)=\left(2 \rho_{1}-1\right) \sum_{i=1}^{I}\left(p_{i 1}^{0} \Delta q_{i}+a \Delta \gamma_{1} q_{i}\right)+\left(1-\rho_{1}\right) \Delta \gamma_{1} \sum_{i=1}^{I} a T q_{i}^{j}-\Delta \gamma_{1} \sum_{i=1}^{I} C F_{i}
$$

Similarly, Formula (2) minus Formula (4):

$$
\begin{aligned}
\Delta E_{1}(\pi M)= & E\left(\pi M^{\prime \prime}\right)-E\left(\pi M^{\prime}\right) \\
= & \rho_{3} \sum_{i=1}^{I}\left[a D_{i}\left(\beta^{\prime \prime}-\beta^{\prime}\right)-\left(C M_{i}^{\prime \prime}-C M_{i}^{\prime}\right)-\left(C T_{1}^{\prime \prime}-C T_{1}^{\prime}\right)\right] \\
& +\left(1-\rho_{3}\right) \sum_{i=1}^{I}\left[a\left(Q_{i}-D_{i}\right)\left(\beta^{\prime \prime}-\beta^{\prime}\right)-\left(C M_{i}^{\prime \prime}-C M_{i}^{\prime}\right)-\left(C T_{1}^{\prime \prime}-C T_{1}^{\prime}\right)\right]
\end{aligned}
$$




$$
\Delta \beta=\beta^{\prime \prime}-\beta^{\prime}, \Delta C M_{i}=C M_{i}^{\prime \prime}-C M_{i}^{\prime}, \Delta C T_{1}=C T_{1}^{\prime \prime}-C T_{1}^{\prime},
$$

Also because $C M_{i}=p_{i 1} Q_{i}, C T_{1}=C T_{1}\left(Q_{i}\right)\left(\gamma_{2}^{\prime \prime}-\gamma_{2}^{\prime}\right)$, so, $\Delta C M_{i}=a Q_{i} \Delta \gamma_{1}, \Delta C T_{1}=C T_{1}\left(Q_{i}\right) \Delta \gamma_{2}$,

That is into the Formula (15), can be simplified:

$$
\Delta E_{1}(\pi M)=a\left(2 \rho_{3}-1\right) \Delta \beta \sum_{i=1}^{I} D_{i}+a\left[\left(1-\rho_{3}\right) \Delta \beta-\Delta \gamma_{1}\right] \sum_{i=1}^{I} Q_{i}-\Delta \gamma_{2} \sum_{i=1}^{I} C T_{1}\left(Q_{i}\right)
$$

\subsection{Game Effect Analysis between Supermarket and Logistics Company}

Logistics company is mainly responsible for the shipment of fresh agricultural products, and carry out a full range of control of the quality and safety of fresh agricultural products, so that the fresh level of agricultural products can maintain the best. But, at present many logistics companies do not pay great attention to maintain the fresh level agricultural products, a large number of agricultural products will be corruption, wilt and so on when they are shipped to the destination. For such a situation, the supermarket can do nothing, only to try to adjust the prices of agricultural products, so that the agricultural products sold out. But in this way, the profits of the supermarket will be reduced with the loss of the fresh level of agricultural products. So, if the supermarket and logistics company signed the fresh-keeping contract, then the logistics company will pay extra attention to the agricultural products freshness protection. In the transport process, it will use appropriate measures to achieve good preservation of agricultural products. In this way, the freshness of agricultural products can be maintained, supermarkets also need to pay extra cost of preservation. Once the logistics company defaults, it will pay a certain amount of liquidated damages. So, whether sign the contract or not, supermarkets and logistics companies have their own consideration. However, if the parties do not agree on the contract, then the two sides do not cooperate, the expected profit is 0 .The game matrix of supermarket and logistics company as is shown in Table 3.

Step 1. Both sides sign the contract

$$
\begin{gathered}
E\left(\pi T^{\prime \prime}\right)=\rho_{2}\left(C T_{1}^{\prime \prime}-C T_{2}^{\prime \prime}\right)+\left(1-\rho_{2}\right)\left(C T_{1}^{\prime \prime}-C T_{2}^{\prime \prime}-L\right) \\
E_{2}\left(\pi M^{\prime \prime}\right)=\rho_{2}\left[\sum_{i=1}^{I}\left(p_{i 2} D_{i}^{\prime \prime}-p_{i 1} Q_{i}\right)-C T_{1}^{\prime \prime}\right]+\left(1-\rho_{2}\right)\left[\sum_{i=1}^{I}\left(p_{i 2} D_{i}^{\prime \prime}-p_{i 1} Q_{i}\right)-C T_{1}^{\prime \prime}+L\right]
\end{gathered}
$$

Step 2. Both sides did not sign the contract

$$
\begin{gathered}
E\left(\pi T^{\prime}\right)=1 \times\left(C T_{1}^{\prime}-C T_{2}^{\prime}\right) \\
E_{2}\left(\pi M^{\prime}\right)=1 \times\left[\sum_{i=1}^{I}\left(p_{i 2} D_{1}^{\prime}-p_{i 1} Q_{i}\right)-C T_{1}^{\prime}\right]
\end{gathered}
$$

Step3. Game analysis

$$
\begin{gathered}
\Delta E(\pi T)=E\left(\pi T^{\prime \prime}\right)-E\left(\pi T^{\prime}\right)=\left(C T_{1}^{\prime \prime}-C T_{1}^{\prime}\right)-\left(C T_{2}^{\prime \prime}-C T_{2}^{\prime}\right)-L\left(1-\rho_{2}\right) \\
\Delta E_{2}(\pi M)=E_{2}\left(\pi M^{\prime \prime}\right)-E_{2}\left(\pi M^{\prime}\right)=L\left(1-\rho_{2}\right)+p_{i 2}\left(D_{i}^{\prime \prime}-D_{i}^{\prime}\right)-\left(C T_{1}^{\prime \prime}-C T_{1}^{\prime}\right)
\end{gathered}
$$

Because $C T_{1}=C T_{1}\left(Q_{i}\right) \gamma_{2}, C T_{2}=C T_{2}\left(Q_{i}\right) \gamma_{2}$. So, $C T_{1}^{\prime \prime}-C T_{1}^{\prime}=C T_{1}\left(Q_{i}\right) \Delta \gamma_{2}, C T_{2}^{\prime \prime}-C T_{2}^{\prime}=C T_{2}\left(Q_{i}\right) \Delta \gamma_{2}$, $\Delta D_{i}=D_{i}^{\prime \prime}-D_{i}^{\prime}$, available in (22) and Formula (23):

$$
\Delta E(\pi T)=\Delta \gamma_{2} \sum_{i=1}^{I}\left[C T_{1}\left(Q_{i}\right)-C T_{2}\left(Q_{i}\right)\right]-L\left(1-\rho_{2}\right)
$$

Table 3. Game matrix between supermarket and logistics company.

Expected profit

Sign fresh-keeping contract

Do not sign fresh-keeping contract
Sign fresh-keeping contract

$E_{2}\left(\pi M^{\prime \prime}\right), \quad E\left(\pi T^{\prime \prime}\right)$

0,0
Do not sign fresh-keeping contract

0,0 


$$
\Delta E_{2}(\pi M)=L\left(1-\rho_{2}\right)+\sum_{i=1}^{I} p_{i 2} \Delta D_{i}-\Delta \gamma_{2} \sum_{i=1}^{I} C T_{1}\left(Q_{i}\right)
$$

From Formula (24) and Formula (25), it can be seen that the expected return of fresh-keeping contract is only related to the total transportation quantities, the effort of fresh-keeping of the logistics company, the probability of default and the default payment, has nothing to do with the agricultural products price and other factors.

\section{Model Results Analysis}

\subsection{Game Result Segmentation}

Through the analysis of the game between supermarket and farmer, the supermarket and logistics company, respectively, the expected profit of sign the fresh-keeping contract minus the expected profit of not sign the fresh-keeping contract, the, get the Formulas (15), (17), (24) and Formula (25). The four results will be analyzed respectively.

For Formula (15), $C F_{i}=c_{i} T q_{i}^{j}=\bar{c} T q_{i}^{j}$, the $c_{i}$ is the unit cost of agricultural products, $\bar{c}$ is the average cost of agricultural products, then:

$$
\left(1-\rho_{1}\right) \Delta \gamma_{1} \sum_{i=1}^{I} a T q_{i}^{j}-\Delta \gamma_{1} \sum_{i=1}^{I} C F_{i}=\left[a\left(1-\rho_{1}\right)-\bar{c}\right] \Delta \gamma_{1} \sum_{i=1}^{I} T q_{i}^{j} \text {, also because } a\left(1-\rho_{1}\right) \geq \bar{c} \text {, So the Formula (15) }
$$

is constant greater than 0 ,that is, the expected profit of signing the fresh-keeping contract is greater than that the expected profit not signing the fresh keeping contract. For Formula (17), $C T_{1}\left(Q_{i}\right)=c_{1} \sum_{i=1}^{I} Q_{i}, c_{1}$ is per unit transportation cost required by the supermarket. Assume that the supermarket procurement of agricultural products just can be sold, that is supply and demand is equal, then the Formula (17) can simplify as

$$
\left(a \rho_{3} \Delta \beta-a \Delta \gamma_{1}-c_{1} \Delta \gamma_{2}\right) \sum_{i=1}^{I} Q_{i} \text {. }
$$

For Formula (24), (25), because $C T_{1}\left(Q_{i}\right)=c_{1} \sum_{i=1}^{I} Q_{i}, C T_{2}=c_{2} \sum_{i=1}^{I} Q_{i}$, among them, $c_{2}$ is per unit transportation cost required by the logistics company. Then Formula (24) is $\Delta \gamma_{2}\left(c_{1}-c_{2}\right) \sum_{i=1}^{I} Q_{i}-L\left(1-\rho_{2}\right)$, Formula (25) simplified as $L\left(1-\rho_{2}\right)+\sum_{i=1}^{I} p_{i 2} \Delta D_{i}-c_{1} \Delta \gamma_{2} \sum_{i=1}^{I} Q_{i}$.

To sum up, the expected profit margin after simplification is shown as follows:

$$
\begin{gathered}
\Delta E(\pi F)=\left(2 \rho_{1}-1\right) \sum_{i=1}^{I}\left(p_{i 1}^{0} \Delta q_{i}+a \Delta \gamma_{1} q_{i}\right)+\left[a\left(1-\rho_{1}\right)-\bar{c}\right] \Delta \gamma_{1} \sum_{i=1}^{I} T q_{i}^{j} \\
\Delta E_{1}(\pi M)=\left(a \rho_{3} \Delta \beta-a \Delta \gamma_{1}-c_{1} \Delta \gamma_{2}\right) \sum_{i=1}^{I} Q_{i} \\
\Delta E(\pi T)=\Delta \gamma_{2}\left(c_{1}-c_{2}\right) \sum_{i=1}^{I} Q_{i}-L\left(1-\rho_{2}\right) \\
\Delta E_{2}(\pi M)=L\left(1-\rho_{2}\right)+\sum_{i=1}^{I} p_{i 2} \Delta D_{i}-c_{1} \Delta \gamma_{2} \sum_{i=1}^{I} Q_{i}
\end{gathered}
$$

\subsection{Summary of Results}

For farmer, because $\Delta E(\pi F)$ is constant greater than 0 , so there is a dominant position when sign the fishkeeping contract.

For logistics company, $\Delta E(\pi T)$ is not only related to the degree of fresh-keeping effort, but also related to the liquidated damages. 
Only when $0<L<\Delta \gamma_{2}\left(c_{1}-c_{2}\right) \sum_{i=1}^{I} Q_{i} /\left(1-\rho_{2}\right), \Delta E(\pi T)$ is constant greater than 0 , there is in a dominant position of logistics company when sign the fish-keeping contract. Otherwise $\Delta E(\pi T)$ is less than 0 , there is a dominant position of not signing the fish-keeping contract.

For the supermarket, there are two parties to the game, one side is the farmer, the other is the logistics company. From the above, it have been proven that there is an advantage of farmer sign the fresh-keeping contract, so, the farmer will sign the contract and then the supermarket will also sign the contract. The logistics company whether sign the fresh-keeping contract is determined by the size of the liquidated damages. If the supermarket wants the logistics company to sign the fresh-keeping contract, that $\Delta E_{2}(\pi M)$ must be constant greater than 0 , in this case, $L>\left(c_{1} \Delta \gamma_{2} \sum_{i=1}^{I} Q_{i}-\sum_{i=1}^{I} p_{i 2} \Delta D_{i}\right) /\left(1-\rho_{2}\right)$.

So, when the supermarket play game with logistics company, if $w_{1}=c_{2} \Delta \gamma_{2} \sum_{i=1}^{I} Q_{i}$ is equal to $w_{2}=\sum_{i=1}^{I} p_{i 2} \Delta D_{i}$, there is not important to sign the contract logistics company and supermarket; if $w_{1}=c_{2} \Delta \gamma_{2} \sum_{i=1}^{I} Q_{i}$ is greater than $w_{2}=\sum_{i=1}^{I} p_{i 2} \Delta D_{i}$, then, there is no overlapping range of default payments, logistics companies want the liquidated damages are less, but if the default payment is too small, the supermarket cannot benefit, so the supermarket will not agree to its cooperation; if $w_{1}=c_{2} \Delta \gamma_{2} \sum_{i=1}^{I} Q_{i}$ is less than $w_{2}=\sum_{i=1}^{I} p_{i 2} \Delta D_{i}$, Then there is room to discuss the setting of liquidated damages, supermarkets and logistics companies can reach a common agreement to sign fresh-keeping contract, Then , the negotiation range of liquidated damages $L$ is

$$
\frac{c_{1} \Delta \gamma_{2} \sum_{i=1}^{I} Q_{i}-\sum_{i=1}^{I} p_{i 2} \Delta D_{i}}{1-\rho_{2}}<L<\frac{c_{1} \Delta \gamma_{2} \sum_{i=1}^{I} Q_{i}-c_{2} \Delta \gamma_{2} \sum_{i=1}^{I} Q_{i}}{1-\rho_{2}}
$$

As long as the default payment $L$ is in range of this negotiation, the supermarket and logistics companies can benefit from the fresh-keeping contract.

\section{Conclusions}

This paper gives the game analysis of fresh-keeping contract between the supermarket and the farmer, the supermarket and the logistics company in the background of farm to market. Supermarket and farmer sign the fresh-keeping contract of fresh agricultural products to ensure the quality of agricultural products produced by farmers. Supermarket and logistics company sign the fresh-keeping contract of fresh agricultural products to ensure that the logistics company maintains the freshness of agricultural products and reduces unnecessary losses in the transport of agricultural products. In the whole analysis of the model, the effort factor maintaining the quality of agricultural products of farmer and logistics company respectively is set, and fresh level parameters are added to make the analysis more rational and logical. In game analysis, with expected profit as evaluation index, this paper discusses the income and expenditure of farmers, logistics companies and supermarkets, lists the expected profit of signing the fresh-keeping contract and not signing the fresh-keeping contract, and then gives the comparative analysis.

The following conclusions can be obtained from the results. First, when farmer and supermarket sign the fresh-keeping contract of fresh agricultural products, the farmer and the supermarket will both benefit from the fresh-keeping contract. Second, whether supermarket and logistics company sign the fresh-keeping contract is determined by $w_{1}, w_{2}$. If $w_{1}=w_{2}$, it doesn't matter whether the supermarket and the logistics company sign the contract, because the profit is equal to the expected profit. If $w_{1}>w_{2}$, supermarket and logistics company will not choose cooperation. If $w_{1}<w_{2}$, then there should be a reasonable negotiation of liquidated damages, so the two sides can decide whether to sign a contract, As long as the liquidated damages are in a reasonable range, supermarket and logistics company will both benefit from signing a fresh-keeping contract. 


\section{Funding}

Key project of Philosophy and Social Science Research in Beijing (09AbJG299); Key project of training plan of Beijing young top-notch talent (CIT \& TCD201304109); Key projects of innovation and Entrepreneurship of Beijing Wuzi University (0541605843).

\section{References}

[1] Gu, W.R. and Li, J. (2011) Reflections on Improving the Work of "Farmer-Supermarket Direct-Purchase” in China. Agricultural Economics and Management, 5, 91-96.

[2] Ren, W.H. and Fan, K. (2013) Research on the Problem of "Farmer-Supermarket Direct-Purchase" in China. Oriental Forum, 2, 119-125.

[3] Shen, M. (2010) Research on Linkage Benefit Based on "Farmer-Supermarket Direct-Purchase” Mode. Agricultural Economy, 11, 70-72.

[4] Zheng, P. and Li, C.G. (2012) Surplus Distribution and Regulation of in "Farmer-Supermarket Direct-Purchase”. Issues in Agricultural Economy, 9, 77-85.

[5] Zhen, G.G. (2011) Eight Problems to Be Solved of “Farmer-Supermarket Direct-Purchase”. China Market, 15, 24-26.

[6] Li, J.P. and Wang, J.P. (2013) Research on the Mode and Mechanism Innovation of Agricultural Product Marketing. Issues in Agricultural Economy, 11, 31-35.

[7] Shen, M. (2011) The Typical Model of "Farmer-Supermarket Direct-Purchase” and the Choice of Policy Objectives. News World, 6, 285-286.

[8] Sun, Q.Z. (2013) Problems and Countermeasures of Agricultural Super Docking in Supply and Marketing Cooperative. Agricultural Economic Outlook, 12, 34-38.

[9] Wang, J. and Chen, X. (2012) Fresh Produce Retailer's Optimal Options Contracts Procurement Decision Research with Circulation Wastage. Systems Engineering-Theory \& Practice, 32, 1408-1414.

[10] Wang, L. and Dan, B. (2013) A Multi-Item Ordering Model for Fresh Agricultural Products with Time-Varying Customer Utility Affected by Freshness. Journal of Systems \& Management, 22, 647-654.

[11] Wang, L. and Dan, B. (2014) Fresh-Keeping and Pricing Strategy for Fresh Agricultural Product Based on Customer Choice. Chinese Journal of Management, 11, 449-454.

[12] Wang, C. and Chen, X. (2013) Pricing and Coordinating the Fresh Produce Supply Chain with Options Contracts. Forecasting, 32, 76-80.

\section{Submit or recommend next manuscript to OALib Journal and we will provide best service for you:}

- Publication frequency: Monthly

- 9 subject areas of science, technology and medicine

- Fair and rigorous peer-review system

- Fast publication process

- Article promotion in various social networking sites (LinkedIn, Facebook, Twitter, etc.)

- Maximum dissemination of your research work

Submit Your Paper Online: Click Here to Submit

Contact Us: service@oalib.com 